\title{
AiMT
}

Advances in Military Technology

Vol. 11, No. 2 (2016), pp. 253-260

ISSN 1802-2308, eISSN 2533-4123

DOI 10.3849/aimt.01139

\section{Specific Aspects of Bridge Construction in the Central African Republic}

\author{
M. Benda ${ }^{1 *}$, D. Coufal ${ }^{2}$ and J. Sobotka ${ }^{1}$ \\ ${ }^{1}$ Department of Engineer Technology, University of Defence, Brno, Czech Republic \\ ${ }_{2} 153^{\text {rd }}$ Engineer Battalion in Olomouc, Czech Republic
}

The manuscript was received on 1 September 2016 and was accepted after revision for publication on 26 December 2016.

\begin{abstract}
:
The paper deals with an operation of Italian engineers in Central African Republic $(C A R)$. The aim of the operation was to construct the temporary bridge. This operation was supported by $15^{\text {th }}$ Engineering Regiment and the University of Defence. Two soldiers from the $15^{\text {th }}$ Engineering Regiment were sent to CAR to help Italian engineers. During this operation REACH-BACK concept between University of Defence and $15^{\text {th }}$ Engineer Regiment was used. Communication and cooperation between these units was supported by Information Portal of Engineer Corps. The portal works as a support element for REACH-BACK concept.
\end{abstract}

\section{Keywords:}

engineer, Reach-Back, temporary bridges, TMS bridge type

\section{Introduction}

The Central African Republic (CAR) is a separate sovereign state often driven by military conflicts. These conflicts resulted in a civil war in 2012. Fighting between Seléka rebel forces and Anti-Balaka government units has already caused not only thousands of casualties, but also immense damage to numerous construction and transport objects. The insufficient transport infrastructure with damaged bridges and roads, was considerably paralysed due to the fact that CAR is a developing country with a very low GDP. After appeasing the conflict, it was necessary to perform a regeneration of these elements, since bridges have become, due to the absence of any other type of transport in the country, a key factor in the framework of the system of transport services across the country.

\footnotetext{
* Corresponding author: Department of Engineer Technology, University of Defence, Kounicova 65, CZ-662 10 Brno, Czech Republic. Phone: +420 973442626 ,

E-mail:martin.benda@unob.cz.
} 
During the fighting in the capital Bangui the bridge (CASTOR Bridge) going over the drainage channel connecting the urban parts Castors and Sica III was also heavily damaged. It was found that, in the framework of transport, it is a central bridge construction, which is used in particular for the transport of trucks with supplies of food and medical supplies. After the assessment of the structure's condition, it was clear that its further use was not possible, and it was necessary to find an adequate substitute as soon as possible.

Due to the ongoing stabilisation mission of EUFOR RCA, a military operation, in this country, Major General Philippe Ponties asked the Czech Republic, through the military representative of the Czech Republic by the EU, for the provision of humanitarian assistance on $20^{\text {th }}$ of September 2014. That consisted of the donation of a temporary bridge with the required load bearing capacity, which should ensure the smooth transportation of cars through the water canal as a replacement for the destroyed bridge CASTOR. The Department of Engineer Technology was responsible for choosing an appropriate bridge construction.

\section{Selection of a Suitable Temporary Bridge}

Specialists on temporary bridges from the Department of Engineer Technology have long-standing experience with their design and construction after the restoration of transport infrastructure after the floods in the period of time from 2002 to 2013. During these years, they designed and constructed nearly 100 temporary bridges with a total length of about $3000 \mathrm{~m}$. The initial limiting requirements for the temporary bridge were the following:

- Military load classification MLC 50.

- The length of the bridge was approximately $24 \mathrm{~m}$.

- The weight of the bridge and the material necessary for the construction up to 40 tons.

Due to the given requirements, it was possible to use temporary bridges MS (Bridge set) and TMS (Heavy Bridge Set). Both temporary bridges are the property of the Czech Republic and are located in the warehouses of The Administration of State Material Reserves (ASMR). For this reason, they could be provided as a humanitarian gift to the Central African Republic.

\subsection{Temporary bridging sets $M S$ and TMS}

Bridging sets MS and TMS are standardized portable steel bridges with two primary trusses and a lower bridge deck. They are used only for a one-way traffic lane with a maximum carrying capacity 60 tons. It is most suitable to build one span bridge with a length of $21 \mathrm{~m}$ and with a carrying capacity of 60 tons for the MS type [1] and one span bridge with a length of $36 \mathrm{~m}$ and with a carrying capacity of 70 tons for the TMS type [2]. It is possible to build a bridge with a longer span, but the carrying capacity has to be reduced. When using a pier (e.g., PIŽMO), it is also possible to build bridges with more spans. The three-meter-long bay is the basic assembly element for both sets (Fig. 1). It is possible to do assembling for both sets with the help of plain rollers, rocking rollers, and a cantilever. The other alternative is to assemble the bridge on flat ground and get it over the obstacle using a suitable crane. The main advantage of the MS type is that it is not necessary to do a special modification of the banks for placing the bridge and ramp. The ramp is created by folding ramps that belong to the end bridge bay. The TMS type needs complex ground shaping, not only for placing but 
also for construction. The ramp for TMS must be done by a special ramp or an abutment wall.

Both bridge sets are not the equipment of Armed Forces of the Czech Republic (ACR). However, they are in the storage of the Ministry of Transport. The soldiers of the Engineering Corps are trained in special courses at the Training Centre of the Ministry of Transport where they get experience with these bridges' construction, as well as with other bridges.
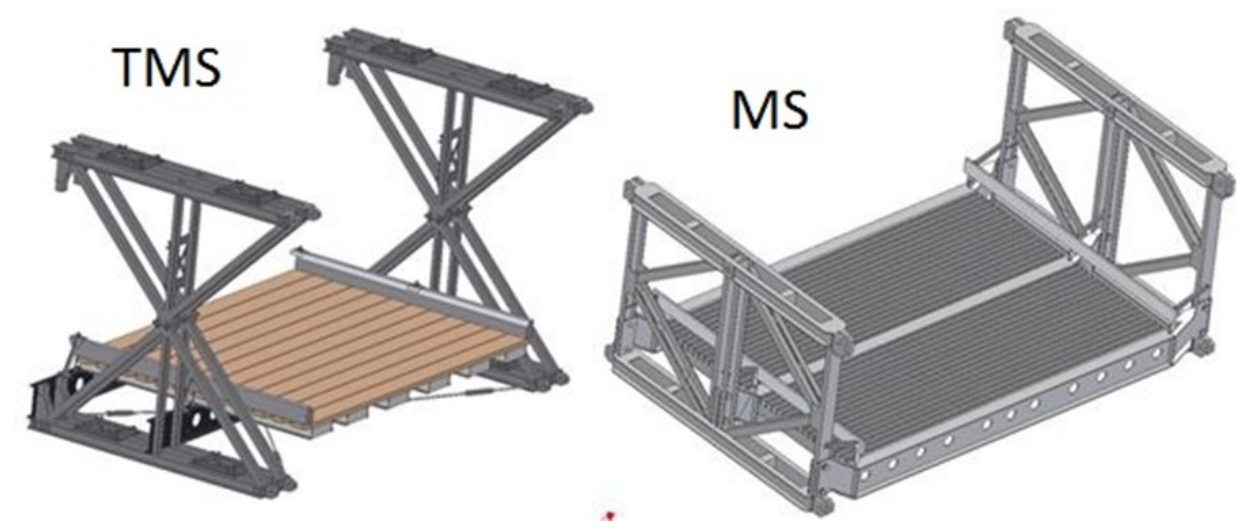

Fig. 1 Model of bay TMS and MS bridge set created by Autodesk Inventor SW

The construction, TMS, a one-storey variant, was selected since it meets all the requirements. The reasons for the selection of this construction were as follows:

- The higher load bearing capacity of the bridge from the MLC compared to the MS.

- The possibilities of taking the construction apart to its individual components and the resulting ease of transport when placing on pallets.

- The possibility of the construction of the one-floor structure without mechanisation.

- The similarity of structure with a Bailey bridge (the construction in the CAR should be carried out by Italian engineers who have experience with the Bailey bridge).

The project documentation for the construction and tools for project architects and the Italian engineers were prepared after the selection of the given variant. These already allow them to become familiar with the structure in theory before the start of the construction.

\section{Project and Proposal of Transportation}

The project documentation, which was an essential part of the construction implementation was prepared after the proposal of the bridge. The drawings of the temporary bridge and the material statement were one of the most important parts of the project documentation. The material statement allowed the preparation not only of the pricing, but it mainly served to calculate the total weight of the transported cargo. In addition to standard drawings and calculations in the project documentation, other support materials were prepared. These materials should serve primarily for the Italian 
engineers to give them the opportunity to familiarize with the temporary bridge and the procedure of its construction. The main tools:

- The manual for the bridge construction, accompanied by illustrative animations .

- Material statement for the bridge construction, launching tracks and launching nose.

- A condensed description of the construction.

- A description and translation of the individual bridge components with illustrative pictures.

All materials were prepared in English with regard to the terminology of the temporary Bailey bridge. It was for this reason that the terminology was as close as possible to the knowledge of the Italian engineers.

The proposal of material transportation to the Central African Republic was also part of the technical bridge documentation. On the basis of the decision of the Command of the Czech Armed Forces, the aircraft AN-124 Ruslan was selected for the transportation of the heavy material, which was provided by Sweden within its allocated hours in the strategic transportation SALIS programme. Due to the nonstandard size of the individual bridge elements, it was necessary to prepare a plan of the layout of these elements on the aeroplane. In total, it was about 1700 parts of dismantled bridge, with a total weight of 45 tons.

For the deployment of the cargo on the aircraft board, it was indicated, in particular, the evenness of the layout. Uneven weight distribution could very negatively affect the gravity centre of the airplane and the flight stability. The material of the heavy bridge construction is typically transported in logically arranged packages and only small parts are transported on pallets (connecting materials and tools). However, it was necessary to store all parts of the heavy bridge construction on pallets for the transportation by aircraft. The reason for the storage of the material on pallets was mostly the easy loading and unloading of the material and its anchoring in the aeroplane. The individual parts of the bridge were placed on pallets (a total of 141 pallet pieces), which were of very non-standard dimensions because of the size of some bridge elements. Members of the $14^{\text {th }}$ Regiment of Logistical Support and a logistics agency ensured the transport from ASMR warehouse in Soběslav and its loading onto the aircraft. The TMS material was transported according to the plan on $12^{\text {th }}$ December, 2014 from Pardubice airport and arrived in Central African Bangui, after a stopover in Madrid, on Sunday $14^{\text {th }}$ December, 2014.

\section{Specifics of the Bridge Construction}

One of the main problems was bridge ramps. In the original request, the length of the bridge was estimated at about $24 \mathrm{~m}$. After a detailed engineering survey carried out directly at the construction site, it was found that it would suffice to put a construction of a total length of $18 \mathrm{~m}$. After consultation with the commander of the project team, it was decided to shorten the length of the structure to a sufficient $18 \mathrm{~m}$. Modified project documentation was prepared, including drawings and immediately sent to the CAR.

The requirement of the suitable ramps was one of the most significant problems that occurred and with which the project team had to deal, together with the commander of the construction. The Czech side was not informed about the ramps requirement in the original request for the bridge construction. The construction ramp request was received during the construction. As a result, a few proposals how to build 
ramps were created. The advantage was that the bridge was shortened to $18 \mathrm{~m}$ and the remaining material could be used for the production of access ramps. The final proposal of the ramps is in Fig. 2. The deck of the ramps was assembled from transoms, stringers, chords and wooden chess. The stability of the transoms was secured using the remaining trusses as stabilisation support. This non-standard solution was used due to the fact that the component used as the support under the transoms was not available.

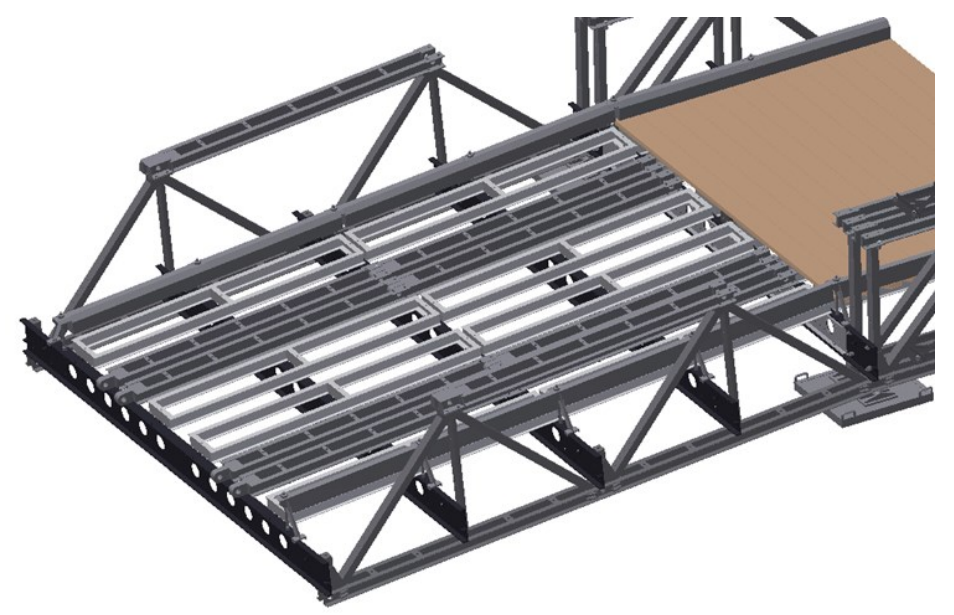

Fig. 2 Final ramp proposal

Due to the fact that, instead of stringers, were used chords, it was necessary to make an assessment of their load-bearing capacity for the bending stresses to which they were exposed during the ramps' construction. In standard construction chords are located on the top of the main truss-beam and are mainly resisting the pressure stress. The Ansys Workbench Program was used for the evaluation. It is a program that uses the finite element method in the calculations. The custom 3D models that were used for the static analysis were created in the Autodesk Inventor program and then imported into the environment of the Ansys Program. 3D construction models were used not only for a static survey of the chords, but also for the creation of the project documentation.

The live load was represented by hypothetical vehicle MLC 50, specifically its heaviest axle weighing 18.14 tons. Evaluated steel elements are rolled I and U profiles 120 made of steel S 355. Stringers and a pair of chords, which replaced them in the ramps' construction, were exposed to external stresses and the external deformation on the individual elements was compared. The chords were divided into 14566 elements and stringers into 18739 elements. The maximum value of the stress on the chords reached $227.56 \mathrm{MPa}$ and the stress on the stringers reached the value $213.63 \mathrm{MPa}$. From the calculated values, it is clear that the value of the chords is approximately $5 \%$ bigger than the value of the stringers. However, it does not exceed the yield point of steel S 355. The progress of the tension is evident from Fig. 3.

\section{Construction}

TMS material arrived in Bangui on $16^{\text {th }}$ December, and was immediately transported from the EUFOR-RCA airport to the main military headquarters of the mission, base 
UCATEX. Two soldiers from the $15^{\text {th }}$ Engineering Regiment were designated construction managers, who arrived at the place on $3^{\text {rd }}$ January, 2015. Soldiers from the $2^{\text {nd }}$ Construction Company of the Engineering Battalion of Trento from Italy were assigned for the construction work. Due to their experience with the construction of a similar temporary Bailey Bridge, they had the best prerequisites for the realisation of the bridge. On the basis of a conversation with the mission commander, it was decided to do repeated reconnaissance of the construction side, the assessment of the possible critical sections and to obtain the exact parameters for the bridge construction. Probably because of the inaccurate measurement of the previous reconnaissance group, it was found that the obstacle was not 18 but only 13.5 metres wide. For this reason, it was decided to build a temporary bridge of 6 bridge fields and the length of the bridge was 18 metres instead of the original 24 metres.

The training for the construction started with theoretical preparation, in which the project commander presented the individual construction parts of the bridge, the terminology and the construction principles of the given components to the soldiers. The complete bridge was built for a test, launching out to the obstacle and placing the bearings were simulated. Due to the unstable political and security situation in the country, the mission commander decided to build up a bridge construction during one day. The reason was a potential danger to soldiers building the bridge construction, and also the possibility of theft of movable and demountable parts of the structure. However, it was an extra requirement, because a bridge of this type and arrangement is usually built over $2 \div 4$ days, depending on the weather and the experience of the construction manager and building persons. The construction commander decided to build the bridge in sections, so it was realistic to build and put the bridge into operation in one day. It was possible to install such a pre-prepared bridge faster and in a more limited area for construction. The fundamental problem, which occurred while planning the operation, was the need for the trucks to turn in the narrow streets of the urban fabric with excessive cargo. That was solved by shortening the dismounted blocks of two to one, finding suitable detours and closing the greater part of the peripheral perimeter. On the construction site, the existing footbridge was removed and the launching track of the bridge on both banks was measured, due to time saving, a day before building.

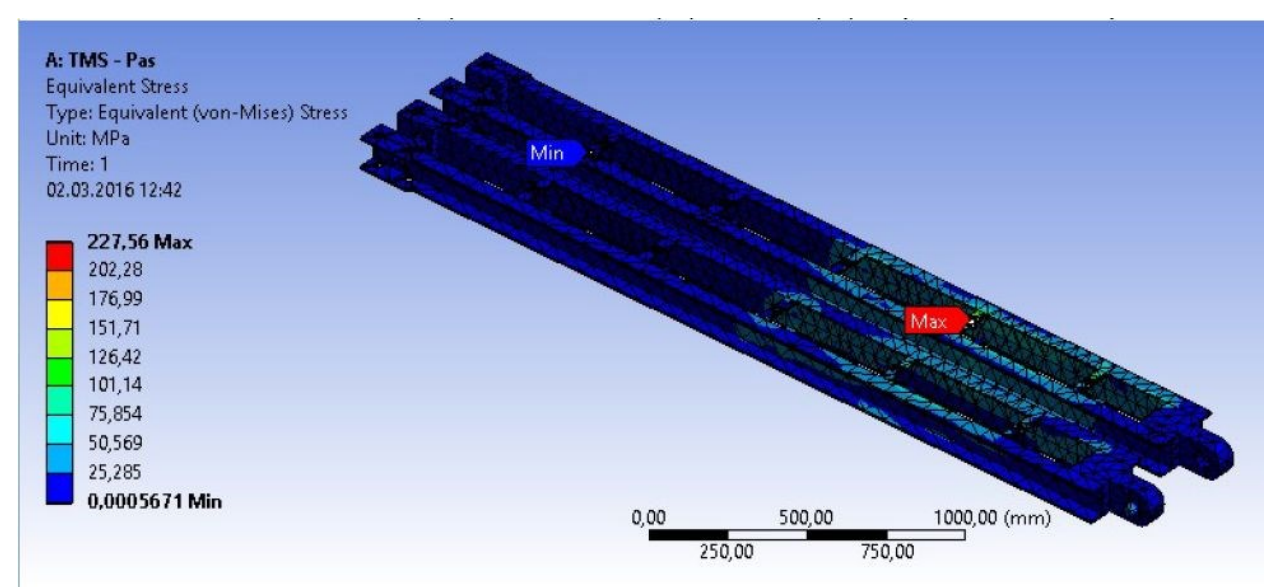

Fig. 3 Calculation model in the Ansys Workbench program 
The bridge construction was launched on $12^{\text {th }}$ January 2015 at 05:00 by the departure of the construction manager and the reconnaissance group to the construction site. The launching track was found partially damaged, with three stopping pins missing. The construction manager performed the corrective measure and defined the extension of the launching path of the bridge. The construction of the temporary bridge was carried out under the schedule below, as already mentioned, within a single day. The time specifies the completion of the work:

- 06:30 - measuring of the launching track;

- 08:30 - installation of the launching track;

- 11:00 - fitting of the launching nose;

- 14:30 - lunch, taking photo, media, the arrival of the delegation;

- 16:00 - bridge built and ready for launching out;

- 18:00 - bridge launching out + removal of launching track;

- 20:30 - placing the bridge on both banks.

After the construction of the access ramps (see section 4), a loading test of the bridge structure was done, where the weight of the vehicles should reach the exclusive load bearing capacity of the bridge. The bridge was loaded only by $40 \%$ of its maximum load bearing capacity, based on the decision of the EUFOR-RCA mission commander. The measured values of the transoms deflection matched the calculation model for this case. This bridge was, by this stage, ready for use by road traffic.

\section{Conclusion}

The project of the temporary bridge in the CAR, including the transportation of the material and its realisation, was a great test, especially for the participating subjects of the ACR and ASMR. It was necessary to deal with the various obstacles that gradually appeared during the whole event. However, it was very important to meet all obligations and implement all actions so that the ACR was still rated as a reliable allied partner.

The preparation of the project documentation of the temporary bridge was a standard task for the members of the Department of Engineer Technology, which they had repeatedly carried out during floods or different exercises many times already [3]. Small complications were caused by insufficient information about the place of construction, since only informational map data and especially the poorly measured length of the bridge were available. Project documentation and drawing were created by the help of extensive database of temporary bridges, which is part Information Portal of Engineer Corps (IPEC) [4]. For the purposes of this project, a new folder in the IPEC environment was created that contains all the relevant data to be available not only to the members of the project team but also to all other interested persons. A non-standard task was also processing a plan of the loading of individual bridge elements on the palette and their layout on the plane because the individual parts are usually transported in logically arranged packages.

The biggest problem was represented by the requirement of access ramps at the moment when the material for the bridge construction was already in the CAR. For the building of access ramps, there are special parts in the kit of the TMS, with which, however, it was not counted when calculating the material. Therefore, it was necessary to propose a non-standard solution to the access ramps. But the project team found a solution even for this problem and the resulting solution of the ramps is fully functional. Another specific aspect of the construction of the bridge in the CAR was 
the fact that the construction unit consisted of members of the $2^{\text {nd }}$ Construction Company of the Engineering Battalion of Trento, which was commanded by members of ACR. In addition, the Italian soldiers were not familiar with the temporary TMS bridge, they had experience only with the Bailey Bridge.

The whole process of the bridge construction was further complicated by specific climatic conditions in the CAR and, in particular, by the security situation in Bangui. For this reason, it was necessary to build a bridge in one day and even in demanding weather conditions. On $12^{\text {th }}$ January, 2015, the bridge was completed and the endurance test was performed. This unique international logistic operation examined the abilities of the engineer specialists of ACR, including the provision of humanitarian donations from ASMR to African countries. In conclusion, we can say that the participating subject of ACR and ASMR completed the task at a very high level.

\section{Acknowledgement}

The paper is based on outcomes of the research project K203-SV-2014 supported by the Ministry of Education, Youth and Sport.

\section{References}

[1] Guidelines for the Use of Bridges MS in the Civilian Sector. Praha: Pontex, 1996.

[2] Heavy Bridge Set TMS: The Use Temporary Bridges TMS. Praha, Ministry of transportation. 2010.

[3] SOBOTKA, J. and BENDA, M. New Possibilities of Temporary Bridges Designing. In International Conference on Military Technologies 2013. Brno: University of Defence in Brno, 2013, ISBN 978-80-7231-917-6.

[4] MAŇAS, P. and MAZAL, J. The Reach-Back Concept in The Czech Army Corps of Engineers. In International Conference on Military Technologies 2009. Brno: University of Defence in Brno, 2009, ISBN 978-80-7231-648-9. 